\title{
An unfinished project or the dispute over the reform of higher education continued
}

\begin{abstract}
This text is a contribution to the discussion on the reform of higher education in Poland. By referring to selected examples, it shows that the planned changes are based on several fundamental myths resulting from the inefficiency of earlier attempts to heal the university system. At the same time, it aims to show why it is necessary to abandon the belief that higher education can be reformed quickly, with little financial outlays, and that the results of the implemented changes can be instant. The text offers also a criticism of the view assuming that the expected changes can be arrived at only through a reform of the law, and that it is possible to transplant solutions functioning in other countries directly to Poland. The presented considerations oppose the position according to which there exist some ideal models of education and research, whose implementation can make it possible to "breed" an ideal scholar. Arguing that education and academic success will always be an outcome of many variables, a critical analysis of selected solutions included in the law on science and higher education has been offered as well.
\end{abstract}

Keywords: Keywords: higher education, reform, university model, internationalisation of education

1 Prof. Wojciech Cyrul - Jagiellonian University, Faculty of Law and Administration, Department of Philosophy of Law and Legal Ethics; e-mail: cyrulwojciech@hotmail.com; ORCID: 0000-0002-5629-869X.

2 Prof. Jerzy Stelmach - Head of the Chair of Department of Philosophy of Law and Legal Ethics, Jagiellonian University, Faculty of Law and Administration; e-mail: jstelmachivr@gmail.com; ORCID: 0000-0002-4188-5277. 
$\mathrm{T}$ he dispute over the model of university education, with university understood in the broadest way possible, has lasted since the universities were established, and will probably last forever. The parties to this dispute are, on the one hand, the academic community and, on the other, politicians deciding on money. However, this does not mean that the main participants of the debate speak with one voice. Not at all! Each group has its own interests, usually contrary to the interests of the other. When it comes to the academic community, the "natural law" or "medical practitioners", or "specialists in the humanities" will speak about the reform differently. We will come across a similar diversity among politicians. The reform will be seen differently by right-wing politicians, differently by liberals, and likewise by the far-left. Basically, everyone disagrees on everything with each other. But, surprisingly, there are some issues of common interest to everyone, but these are egoism and minimalism. Each of those participating in this debate ignores the arguments of others, and additionally wants to change the system so that everything remains unchanged. And that is why we will probably have to keep on "talking" and "reforming" for some more time to come. And the Campus will probably stay as it has been before because eventually it will turn out, as usual, that there is no money for the reform.

The ineffectiveness of many different - not only Polish - reforms results from at least six myths, which underlie the thinking about the idea of university recovery. The first myth is that you can do it quickly. Everyone, both academic teachers and politicians, expects immediate results; the former expect more privileges and wider autonomy, and the latter - a message that can be used for propaganda purposes. And yet, even the people who are not so well familiar with the functioning of a university must be aware that the results, if any, of certain reforms may take shape only after many years. A rational reform means a long-lasting process that in fact lasts for at least a generation and covers evolutionary changes, during which the way of thinking about the university of the entire scientific community is changed. In particular, new qualitative and quantitative standards should be developed and applied in this process to assess the quality of scientific and teaching work. The second myth is that it can be achieved only through a law reform. The easiest and fastest way is to prepare and pass a new act of parliament. It is much harder to bring it into force; in other words - to actually implement the announced reform. Usually the proposed changes included in an act of parliament are more a manifestation of "wishful thinking" rather than an actual reform programme. That is probably 
why the debate about its change begins as soon as the new law is passed. The third myth is that it is possible to apply the solutions working elsewhere directly. Both scholars and politicians look for the perfect model of university reform, with a zeal worthy of a better cause. Most proponents of radical changes in Poland support the adoption of solutions functioning in other academic systems, mostly Anglo-Saxon ones. In particular, the solutions developed there for the "score-based assessment of the value of scientific publications" and "the rules for assessment of quotations" are transplanted to our reality without any questions. And the only results so far have been our best universities ranking very low in rankings "invented" by others, just like in case of other solutions. Anyone who has had the opportunity to get to know some of the top-ranking universities, where, to say the least, nothing special happens, must admit that this method of assessment is grossly unfair. Playing the game by someone else's rules, we condemn ourselves to marginalisation. Myth four is that you can do it without much money. This myth is based on the conviction that it is enough to try harder, and success will simply follow. We pass a new law, make some vague promises to the academic community, and everything will go in the right direction. This is obviously nonsense, and a bit more about it can be said by referring to the example of Harvard University, often quoted by the "reformers" anyway. This otherwise outstanding university has financial resources in amounts comparable to those allocated to the entire sector of higher education in Poland. Apart from huge financial reserves, Harvard receives a very high state subsidy, earns a lot of money on education, and finally receives countless donations from institutions and individuals. So what are we talking about here? The case of Harvard shows only that it is necessary to fight the myth discussed here, and that money should be diversified if it is to effectively serve the development of a given academic institution. The fifth myth is that it is relatively easy to "breed" an ideal scholar. Again, in our opinion, it is all about a completely false idea that it is possible to regulate education and development of academic staff by way of an act, that the reform alone will do, and we will then start succeeding. It will be enough to abolish the institution of habilitation, simplify the promotion procedure, increase the number of doctoral students, and the "breeding" will start in full swing. At this point, we should remind the reader about the total failure of the "junior professors" programme in Germany, or note, as already mentioned before, that the use of promotion solutions developed in other places, for example in Anglo-Saxon countries, may prove to be completely ineffective in another environment and tradition. And so, a necessary condition for the development of staff in the natural sciences will be to participate in transnational research programmes and collaborate with the best research centres in the world. On the other hand, the humanities will always be only about "hunting for" individuals who have never been "bred" anywhere on 
a larger scale. The sixth myth is that an "optimal model of education" can be created. Education will always be a resultant of many variables. Above all, a resultant of determinants such as a specific political and economic situation of a given country, tradition of a given place, effectiveness of the previously used methods and the possible effectiveness of the suggested ones, the quality of staff at a given academic centre, and, finally, varying motivations of students in various periods. It is, in fact, a continuous process of changes and adjustments, where nothing can be determined once and for all, and certainly not by means of provisions of an act of parliament.

The formal basis for any possible reform should be essentially similar. Firstly, the main goal of the reform should be clearly defined. It should be considered in particular which university model you will want to suggest; an elite university, meaning a university for the privileged, or an egalitarian university, meaning a university sort of for everyone. Any attempt to combine them, to find a compromise between these two points of view, will always lead to a failure of the reform. Secondly, there are a few key assumptions that should be made, that is, to adopt a programme of what is strictly necessary, which would cover key issues such as: university autonomy, decentralisation of the management system, consistent parameterisation rules (academic assessment) addressing the specificity of a given system, instead of mindlessly adopting them from outside, competitions for the academic staff at the university, ways of employing academic staff, and - finally - wage diversification. It is only after determining and discussing such assumptions that attempts can be made to create a coherent reform model. Starting our reform with thousands of provisions of a detailed regulation is, in our opinion, a project doomed to failure. Unfortunately, such a solution was adopted on 3 July 2018 by the Sejm of the Republic of Poland by passing the new Law on Higher Education and Science.

We will not dissect particular provisions of the act now, there will be time for that later. What is more important now is the question whether the adoption of the new law really means a revolution in the higher education system or whether it is only an expression of unfulfilled ambition of a part of the academic community and politicians' attempt to sugar-coat the reality. Or maybe we are dealing with a reasonable transformation and ordering of the higher education system, involving an implementation of solutions that give much greater opportunities for Polish science to internationalise than it has had so far? Unfortunately, the main goals of the reform, i.e. sustainable development and internationalisation of Polish science and higher education, are so general that it is difficult to assess the reform without analysing the means through which the reformers intend to pursue their goals. Regretfully, there is a lot evidence that these goals are based on the same myths that we covered earlier. For example, it is difficult to understand how the new rules for the parameterisation of science are to support the development of humanities, 
how the implemented reform of the education model for doctoral students is to improve the quality of their education, and how the new academic career paths introduced by the legislator are to improve the quality of education and scientific work if they do not come accompanied by any new incentive instruments. There are similar doubts about the changes in the rules for employing academic staff. In particular, it is not clear how they are to support the development of Polish science and its internationalisation, given that the law excessively supports stability of employment of persons employed based on contracts of employment and, at the same time, has a negative impact on academic teachers employed on the basis of appointment, which are mostly people with the academic title of professor. It also does not make any real changes to the salary system for academic staff and weakens the role of competition proceedings instead of strengthening them. Bearing in mind these and other doubts, one cannot resist the impression that the reform deepens the pathologies existing in the system rather than counteracts them. Below, using a few examples, we will try to show that at least some of the doubts are not completely unjustified.

It is difficult to predict whether the new regulations will promote implementation of the values indicated in the preamble. Today, it is also difficult to say with all certainty if the new regulations make it possible to implement the ambitious goals that underlie the reform. However, there are many indications that this time mythical thinking has won over common sense, and that we will witness another unfinished reform again. The original sin of the creators of the new act of parliament is the lack of unambiguous demonstration that the new solutions are able to guarantee a successful implementation of its goals. All the high-flown slogans on professionalisation of university management, on expanding the autonomy of higher education institutions, on new academic career paths, on new rules for assessing scientific achievements, and finally on increasing the expenditure on higher education carry, in fact, nothing special with them. Actually, there are even clearly contradictory solutions hidden behind the declarations. Unfortunately, as usual, either they lacked courage, or animosities or conflicting interests of individual stakeholders interested in maintaining the status quo have won. It is enough to look at the concept of the university council, which is so controversial. It is an institution that is not completely foreign to the Polish higher education system. After all, councils of this type functioned for some time after the amendment to the Higher Education Act of December 1968, hence saying that a solution functioning at the best Western universities is being implemented can only be treated as a rhetorical device. It is not the existence of a university council or lack thereof that is of importance here, but its role, legal status, range of competence, and composition are what matters. In the version of the act adopted by the Sejm, the university council was deprived of 
a range of previously planned executive competencies and was basically reduced to an advisory and supervisory body. Analysing the current nature of this institution, one can come to the conclusion that the only certain effect of its establishment, apart from the obvious limitation of external subjectivity of the university, will be further financial burdens that will have to be borne due to the need to pay remuneration to council members. Of course, it may turn out that the members of this body will be distinguished people whose experience, contacts, and skills will bring a new quality to university management. However, a guarantee that this will be the case is not provided by the new act of parliament because the requirements imposed on the candidates are so low that practically anyone without a criminal record, with higher education, enjoying full public rights, and with full ability to participate in legal transactions can become a member thereof. The act only prohibits combining the membership in a university council with a function in a body of the same or another university, with a membership in the council of another university, and employment in public administration. However, it does not prohibit appointing active politicians, representatives of religious associations or persons who do not guarantee that the office of council member will be exercised in accordance with academic values. A question that arises immediately is why establish a body that can be appropriated by local networks or people who do not guarantee either worldview or political neutrality. We do not accuse anybody of bad intentions or lack of goodwill, but if we want to professionalise the management of universities, we should probably require those whom we entrust something as important as universities that they at least live up to what we demand from those to whom we entrust state property. Paradoxically, the new law explicitly stipulates that the provisions of Article 19 of the Act of 16 December 2016 on the Rules of State Property Management (Journal of Laws of 2018, item 1182) do not apply to university council members. Given the role of the university council, it must also come as a surprise that the chairperson of the student council is obligatorily included in the former's composition. Appreciating the role of student councils in the functioning of universities, and the need to properly represent students in the bodies responsible for matters related to shaping the university's academic policy and teaching, it seems, however, that university councils should include rather prominent experts, representatives of external stakeholders or people whose achievements inspire respect and recognition of the local community, instead of people who are still learning.

There are similar doubts about the far-reaching strengthening of the rector's position, without explicitly tightening the criteria that should be met by people applying for this position. The new law clearly stipulates that the rector's tasks include all matters concerning the university, with the exception of matters reserved by the act of parliament or statutes for the competence of other university bodies. 
Although the idea that the rector would be chosen by the university council has been hopefully abandoned whatsoever, it is still difficult to understand why the rector is so omnipotent and why so many prerogatives are offered to one person. Certainly, this is not justified by the reference to the attempt to implement a manager-based model in university management in Poland. Experience and knowledge of management teach us that excessive centralisation works in favour of an increase in management costs only. The quality of management is promoted by appropriate procedures, competent staff, and adequate control mechanisms. The problem with the solution adopted in the act lies primarily in the fact that the rector, who has been ultimately entrusted with the full executive power at the university, is essentially expected to meet the same criteria as the members of the university council. The only additional requirement is that they should have at least a PhD degree. A rhetorical question is whether a person without a degree in management, without basic legal and economic knowledge, and without many years of international experience in managing a large business or research institution can professionally manage a university, prepare its strategies, and deal with its personnel policy and financial management. Of course, the lack of statutory criteria to be met by rectors and a practice to leave this issue to the discretion of universities is present in some EU countries, such as Austria, the Netherlands or the United Kingdom. However, these countries have a different academic culture than Poland, so if the authors of the reform really wanted to professionalise universities, they should have implemented at least a requirement of international competitions for the rector's post or clearly limit the rector's post to representative and academic functions, and entrust university management to professional managers. Again, there was no overall vision, or people came to believe in the myth that individual academic communities, often lacking adequate resources and experience, would be able to develop and implement appropriate mechanisms in this regard. It is particularly intriguing in this context that the extension of the rector's competence is not accompanied by a simultaneous introduction of clear rules of accountability and transparency of university management. Without such rules, it is difficult to talk about any professionalisation, and it becomes a substantiated accusation that the solution implemented by the act will be conducive to a takeover of decision-making processes at universities by narrow groups of privileged persons, and to a further reduction of subjectivity of other university employees and students.

With regard to all of the foregoing, it seems that easier management of funding streams will not be conducive to more effective expenditure, at least from the point of view of achieving the reform goals. What is more, the abovementioned doubts justify the conclusion that the new structure of the education system, even if it implements many good solutions, such as the possibility of creating a university federa- 
tion, does not guarantee that the system will meet the social and economic challenges it faces. Unfortunately, in the current condition of Polish universities and academic community, believing that reforms can be made quickly, and that it is enough to implement the right legal regulations may prove to be risky, not only for individual universities but also for public finance. The conviction that structural changes can be implemented quickly and that financing can proceed gradually leads to a situation that instead of testing new solutions under pilot programmes in a controlled environment at several selected universities, we see solutions developed and implemented whose effectiveness we cannot be sure about. Common sense and experience suggest that before the entire system changes, you need to check how specific solutions work and see whether the effects to which they lead are consistent with expectations or not. However, no such attempts have been made. It turns out again we were incurable romantics driven by emotions instead of reason, choosing spectacular actions, great slogans, and experiments on a living organism over gradual reforms that are well-prepared and based on solutions that worked well in Polish conditions while addressing the specificity of the Polish academic culture and the level of economic development of Poland. Unfortunately, experiments, in particular those ill-prepared and ill-conceived, very often fail, therefore the prophesied success of the reform may simply not happen in the analysed case. Most likely, however, we will have to get through a long period of chaos, and what has been working somehow so far will stop working then.

Megalomania and faith in the myth about the effectiveness of law in managing social change and the conviction of decision-makers of their infallibility have pushed us all into unexplored areas, probably full of good intentions, but supported by neither real knowledge nor experience. Instead of gradually improving the existing institutions, we are adopting new solutions, not yet tested in practice in our culture. Instead of thinking about which university model we have today and why it is the one and not another, we are trying to copy the success of the Anglo-Saxon university model in Poland without money, without a proper business environment, and without the tradition with which this model is associated. Perhaps we should compare the results of Polish universities with the results of universities from the first hundred of the Shanghai Ranking, while taking into account the factor of research and salary budgets. It might turn out that the previous system of higher education, with all its disadvantages, was not as bad as it seemed, and the implementation of incentive mechanisms and support for researchers could significantly increase the impact of their achievements on the global circulation of ideas and improve the results they achieve in grant competitions organised by the European Research Council. In other words, in order to internationalise Polish science, instead of a great reform, it might be enough to better link the salaries and academic results achieved by 
university employees, to provide higher education institutions with funds for employment of outstanding foreign researchers, to create real incentives, and to provide support to researchers ready to submit applications in European grant competitions, and to take better advantage of the academic potential of higher education institutions in state projects.

Given that the reform provides for an increase in expenditure on science in total by almost PLN 50 billion over the next decade, the question arises whether the new law guarantees that such money will be ensured definitely for the higher education system and whether the solutions adopted by the Sejm guarantee that this money is not wasted. Both questions must be left unanswered because there are no reliable and independent analyses that would show clearly which part of this amount will be absorbed by the costs of implementing the reform and what will be the costs of functioning of the new solutions. One can only hope that they will not be much higher than expected in the impact assessment, and that the system will not be fed with less money than the ministry plans. Otherwise it will be another unfinished and failed reform. It should be kept in mind as well that the sum of money that the government plans to spend additionally for the entire higher education system and for science within 10 years is many times smaller than the amount that will be available at the same time to Harvard University. Regardless of the fact that its annual revenue is about USD 5 billion, if nothing changes, it will receive government subsidies for research over the next decade that are larger than the new law plans for all Polish universities combined.

Proponents of the reform demanded changes, and probably rightly so. Poor results of Polish universities in international rankings do not leave any doubts that they are not doing well. In the regulatory impact assessment prepared for the act, the Ministry of Science and Higher Education clearly showed that although the percentage of people with higher education increased significantly in Poland, this translated neither into improving the international status of Polish universities nor into the quality of Polish science. With expenditure on science and development in Poland amounting to $1.0 \%$ of GDP, we rank as low as $31^{\text {st }}$ among the 35 OECD member countries. Many solutions have been proposed, such as increased R\&D expenditure up to the average value of this indicator for OECD countries, i.e. up to $2.5 \%$ of GDP in 2030, or strengthening the financial autonomy of universities by increasing the flexibility in spending funds provided to them by the state, which, in the opinion of the reformers, are to make Polish universities join the industry leaders. An interesting idea is also to start organising competitions under the Research University Excellence Initiative under the Regional Excellence Initiative programme, which will significantly increase the financial resources awarded to winning universities. It is a pity, however, that it was also not decided at that point to implement bolder 
changes, and no mechanisms were introduced that would cause the money for universities follow students. Despite the existing constitutional constraints, an attempt could have been made to implement systems that would privilege universities excelling in teaching, and the competition between universities introduced this way would make it possible to better adapt the teaching offer to the needs of the education market. Unfortunately, without this type of solutions, the quality of education at Polish universities will probably not improve significantly.

Bearing in mind the long-time underfunding of Polish science, it should be appreciated that the outlays for science will finally be increased, but the pace and the rules for granting funds will make Poland rather unlikely to join the most innovative countries in the foreseeable future. The faith of the reformers that the new system, free from the current restrictions, will be better than the previous one gives rise to concerns for every observer of the discussion on the financing and functioning of Polish universities and Polish science. Leaving aside the question of what makes the new system better, we should also remember to leave well alone. We surely do not think that the current system does not need to be changed, but it must be remembered that there were some reasons to establish such an extensive system of rules governing the management of universities and their structures. What is more, decentralisation and empowerment of basic university organisational units in the delivery of higher education, in running doctoral studies, in the awarding of academic degrees and evaluation of scientific and teaching activities is not a disadvantage. On the contrary, although they might limit rectors' effective management of their universities, they are an expression and a guarantee of subjectivity of internal academic communities. It may be necessary to rethink and change the rules of their functioning. However, should they be definitely eliminated? Why should the transfer of the right to offer and teach different programmes and to award academic degrees at the level of faculties to the level of universities improve the quality of teaching? Why should doctoral schools improve the level of qualifications of doctoral students? Isn't it so that the new model of doctoral education, providing for e.g. elimination of part-time doctoral studies and the new rules for granting the right to confer doctoral degrees are simply an expression of faith in the myth that it is possible to "breed" an "ideal scholar"?

What is also surprising about the reform is the attempt to justify the need for changes in the organisation and the system of universities by a lack of external stakeholders in their lives. This astonishment results from the fact that the reason for this state of affairs is not necessarily a faulty university system. In practice, it is the result of a low level of development and a limited economic potential and low innovative profile of Polish enterprises, and thus the incompatibility of university goals and labour market needs. Unfortunately, the human factor is also decisive to the 
lack of collaboration in many cases. So instead of opening new universities or changing the organisation of the existing ones, maybe it would be better to ensure that university managers guarantee a sound management of their universities and that they are accountable for the effects of collaboration with external stakeholders? Furthermore, instead of opening more universities, maybe more vocational colleges or technical universities focused primarily on preparing graduates for highly specialised professions should be established?

Bearing in mind the financial resources currently available to Polish scholars and Polish universities, we can hazard a guess that even if we introduce a statutory division into research universities, vocational colleges or any other, it will not get any better if the financial outlays for science and higher education are not significantly increased. Without a real change in the system of financing science and a significant increase in funding for higher education, without a real change in the salaries of the staff of universities and research institutes, and without effective mechanisms for commercialising the results of scientific work, not much will change regardless of the form of regulation. Although the reform provides for positive changes in this respect, as mentioned above, it is quite surprisingly full of the spirit of egalitarianism and equal distribution for all instead of introducing solutions conducive to competition and concentration of funds. A particular manifestation of this approach is linking the minimum pay of university staff with the salary of professors and awarding scholarships to all doctoral students.

Unfortunately, linking the minimum pay with the professor's salary without clear criteria for calculating the latter neither guarantees long-term material prestige of scientists nor ensures an increased level of activity and mobility of academic staff. It is a pity that salaries have not been linked with average salaries in the state-owned enterprises sector, or that Western-European solutions that link the salaries of science and higher education staff with the salaries in the public administration sector have not been adopted. The current solution, contrary to declarations, not only does not guarantee scientists the option to benefit from economic growth, and additionally, given the dynamics of the salary growth in the market, it will perpetuate the collapse and pauperisation of this environment. Unfortunately, the reformers did not risk making any far-reaching changes that could actually stir Polish science. We still tend to blame failures on the "system" rather than admit that we are driven by fear of mechanisms introducing real competition, which may cause significant personnel changes at all levels and lead to a collapse of poorer performing higher education institutions. Therefore, the regulations adopted in the act of parliament regarding competition proceedings in the employment of academic teachers should be considered insufficient. They will not prevent the possible pathologies in these proceedings, all the more so as universities have not been 
forbidden to employ their graduates, including "fledgling" doctoral degree holders, before they win a competition for an academic position at another university and do not work there for several years. Such a solution could counteract nepotism and increase the mobility among staff, but it would involve a necessity to offer much bigger social guarantees to academic staff.

There are even more reservations with respect to the second solution, which guarantees scholarships to all doctoral students. It eliminates the practical need to struggle for doctoral grants. The current system of doctoral grants, largely based on the activity of the National Science Centre, was far from perfect, but it does not change the fact that it was based on mechanisms of scientific competition. It is difficult to say what the basis for the belief that granting guaranteed scholarships to doctoral students will improve the quality of their work is, but it certainly does not result from the experience of working in committees granting doctoral grants to students or from working with doctoral students. It is naive to believe that providing all doctoral students with scholarships will make them focus entirely on research and that it will improve its quality. In the current situation, when there's not enough money for almost everything in higher education, one should seriously consider whether, instead of 'dispersing' the funds we have and giving everyone a bit, it would not be better to accumulate these funds and allocate much larger amounts for projects and salaries of researchers who are given the best rating by international expert bodies. Although this standpoint may be controversial, it is sometimes better to admit that we simply cannot afford to support everyone equally regardless of the value of a given research programme. The solution introduced by the law seems all the more incomprehensible in that it leads inevitably to effects contrary to what was declared by its authors. Doctoral students and their research projects will not have to be compared in nationwide competitions in which international reviewers are involved, but they will be only compared and evaluated in local competitions organised within a given university. So instead of internationalising Polish science, we see a system that supports local standards and local scientific bodies that promote them proposed already at this stage. However, what should be appreciated is the introduction of a universal system of maternity and paternity leaves for doctoral students.

The above considerations were focused on the doubts raised by the new law on higher education and science. Obviously, because of the scope of this study, we have omitted a number of details. Apart from the considerations covered, there are also solutions that, in our opinion, clearly deserve support, such as the new teaching career path for outstanding teachers, the introduction of solutions promoting quality instead of the number of publications, and financial support for Polish scientific journals. Other, such as the abolition of the habilitation obligation, the introduc- 
tion of measures to facilitate the process of obtaining habilitation in certain situations or the introduction of a principle that the evaluation of scientific research is to take place within the whole university and not only at the faculty level will always lead to controversy and polemics. Only time will tell if these changes meet the expectations of the reformers, or whether we are to see yet another "unfinished reform". Is it possible to make any progress in the university reform without clearly defining the goal and overcoming the ubiquitous "myths"? We are unable to find any serious arguments that could support a negative answer to the first question and an affirmative answer to the second one. So what to do now? Probably what is usually done in Poland - wait. 